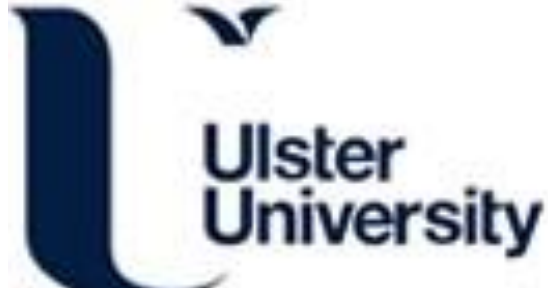

\section{Processing-property relationships of biaxially stretched binary carbon nanofillerreinforced high density polyethylene nanocomposites}

Harkin-Jones, E. (2017). Processing-property relationships of biaxially stretched binary carbon nanofillerreinforced high density polyethylene nanocomposites. Materials Letters, 209, 551-554. https://doi.org/10.1016/j.matlet.2017.08.104

Link to publication record in Ulster University Research Portal

\section{Published in:}

Materials Letters

Publication Status:

Published (in print/issue): 24/08/2017

DOI:

10.1016/j.matlet.2017.08.104

\section{Document Version}

Author Accepted version

\section{General rights}

Copyright for the publications made accessible via Ulster University's Research Portal is retained by the author(s) and / or other copyright owners and it is a condition of accessing these publications that users recognise and abide by the legal requirements associated with these rights.

\section{Take down policy}

The Research Portal is Ulster University's institutional repository that provides access to Ulster's research outputs. Every effort has been made to ensure that content in the Research Portal does not infringe any person's rights, or applicable UK laws. If you discover content in the Research Portal that you believe breaches copyright or violates any law, please contact pure-support@ulster.ac.uk. 


\section{Accepted Manuscript}

Processing-property relationships of biaxially stretched binary carbon nanofiller reinforced high density polyethylene nanocomposites

Dong Xiang, Lei Wang, Yuhao Tang, Eileen Harkin-Jones, Chunxia Zhao, Yuntao Li

PII: S0167-577X(17)31302-2

DOI: http://dx.doi.org/10.1016/j.matlet.2017.08.104

Reference: MLBLUE 23081

To appear in:

Materials Letters

Received Date:

20 July 2017

Revised Date:

15 August 2017

Accepted Date:

23 August 2017

Please cite this article as: D. Xiang, L. Wang, Y. Tang, E. Harkin-Jones, C. Zhao, Y. Li, Processing-property relationships of biaxially stretched binary carbon nanofiller reinforced high density polyethylene nanocomposites, Materials Letters (2017), doi: http://dx.doi.org/10.1016/j.matlet.2017.08.104

This is a PDF file of an unedited manuscript that has been accepted for publication. As a service to our customers we are providing this early version of the manuscript. The manuscript will undergo copyediting, typesetting, and review of the resulting proof before it is published in its final form. Please note that during the production process errors may be discovered which could affect the content, and all legal disclaimers that apply to the journal pertain. 
Processing-property relationships of biaxially stretched binary carbon nanofiller reinforced high density polyethylene nanocomposites

Dong Xiang ${ }^{\mathrm{a} *}$, Lei Wang ${ }^{\mathrm{a}}$, Yuhao Tang ${ }^{\mathrm{a}}$, Eileen Harkin-Jones ${ }^{\mathrm{b} *}$, Chunxia Zhao ${ }^{\mathrm{a}}$, Yuntao Li $^{\mathrm{a}^{*}}$

${ }^{a}$ School of Materials Science and Engineering, Southwest Petroleum University, Chengdu 610500, China

${ }^{\mathrm{b}}$ School of Engineering, University of Ulster, Jordanstown BT37 0QB, UK

Abstract: Different dimensional carbon nanofillers, such as carbon nanotubes (CNTs), graphene nanoplatelets (GNPs) and carbon black (CB), are often incorporated into polymers in a hybrid form to fabricate multifunctional nanocomposites. In this paper, biaxial stretching of binary carbon nanofiller reinforced high density polyethylene (HDPE) nanocomposites was carried out at various stretching ratios in order to investigate the influence of carbon nanofillers on material deformation behaviour and the influence of biaxial deformation on the structure and properties of the deformed material. It is shown that the strain hardening behaviour of nanocomposites upon biaxial stretching is gradually enhanced with increasing aspect ratios of the nanofillers. The deagglomeration and reorientation of nanofillers in the polymer matrix can be observed during deformation. Furthermore, biaxial stretching significantly affects the final tensile, electrical and barrier properties of the deformed nanocomposites, depending on the components of carbon nanofillers introduced. The stretched HDPE/GNP/CNT and HDPE/GNP/CB nanocomposites exhibit greatly improved tensile and barrier properties.

Keywords: Carbon nanotubes; Graphene nanoplatelets; Carbon black; Nanocomposites; Biaxial stretching

\section{Introduction}

The mechanical, electrical and gas barrier properties of polymers can be improved with the addition of carbon nanofillers, such as CB, CNTs and GNPs [1,2]. In order to achieve lower cost or better properties, carbon nanofillers with different dimensions may be introduced into polymers in binary combinations. To date, a significant body of work has been published on the preparation and characterization of polymer composites filled with unary and binary carbon nanofillers, but much less work has been published on the influence of the incorporation of carbon nanofillers on the material 
processability and on the influence of processing on the structuring and properties of the polymer/carbon nanofiller nanocomposites $[3,4]$. Biaxial elongation is an important deformation mode, typical of many free surface moulding processes such as thermoforming, blow moulding and blown film extrusion [5]. Although some recent studies assess the effect of biaxial deformation on polymer/CNT composites [2-6], almost no research has been published on the biaxial deformation of polymer composites filled with binary carbon nanofillers. In this work, the biaxial stretching of binary carbon nanofiller reinforced HDPE nanocomposites was carried out at various stretching ratios (SR) in order to investigate processingproperty relationships of material. This study provides valuable guidance for the processing and property optimization of polymer/carbon nanofiller composites.

\section{Experimental}

High density polyethylene (HTA-108) was sourced from ExxonMobil. Multi-walled carbon nanotubes $(\mathrm{NC} 7000$, aspect ratio $\approx 150)$ with an average length of $1.5 \mu \mathrm{m}$ and a nominal diameter of 9.5 nm were kindly supplied by Nanocyl SA. Graphene nanoplatelets (xGnP-15, aspect ratio $\approx 2000)$ with an average thickness of $6 \sim 8 \mathrm{~nm}$ and an average diameter of $15 \mu \mathrm{m}$ were purchased from XG Sciences. Carbon black (Ketjenblack ECP600JD, aspect ratio = 1) obtained from AkzoNobel has an average diameter of $68 \mathrm{~nm}$ and a porous structure (surface area $=1400 \mathrm{~m}^{2} / \mathrm{g}$ ). The HDPE powder was mechanically premixed with binary nanofillers at a total loading of $4 \mathrm{wt} \%$ (nanofiller weight ratio $=1: 1$ ), then the dry blends were melt mixed in a Collin ZK 25 twin-screw extruder. The extruded nanocomposites were pelletized and compression moulded (CM) using a Collin P200P platen press at $200{ }^{\circ} \mathrm{C}$ into sheets. The CM sheets were simultaneously-biaxially stretched (BS) at a strain rate of $4 / \mathrm{s}$ and a stretching temperature of $131^{\circ} \mathrm{C}$ with increasing SRs of 2, 2.5 and 3 using the Queen's Biaxial Stretcher [5] (SR of 1 refers to the CM samples).

The structure of nanocomposites was examined via a JEOL 6500F FE-SEM after the samples were plasma etched (STS Cluster C005) and gold sputtered. Tensile tests were carried out for the samples using an Instron 5564 Universal Tester (BS EN ISO 527:1996). Volume resistivity testing for samples with a

high resistivity $\left(>10^{5} \Omega \cdot \mathrm{cm}\right)$ was conducted using a Keithley 6517A electrometer equipped with a Keithley 8009 resistivity test fixture (ASTM-D257). For more conductive samples $\left(\leqslant 10^{5} \Omega \cdot \mathrm{cm}\right)$, a two- 
point probe method was applied using a Keithley DMM 2000 multimeter. Barrier properties of samples were investigated using an oxygen gas permeability test with a Labthink VAC-V1 gas permeability tester (GB/T1038-2000).

\section{Results and Discussion}

Fig. 1 shows the structures of the CM and BS composites. In Fig. 1, the GNPs are aligned parallel to the surface of the stretched HDPE/GNP/CNT and HDPE/GNP/CB composites after biaxial stretching at a SR of 3, and the CNTs are disentangled and randomly oriented in the stretched HDPE/GNP/CNT and HDPE/CB/CNT composites. By comparing the morphologies of the unstretched and stretched composites in Fig. 1, it can be seen that the carbon nanofillers are dispersed more uniformly for all the binary carbon nanofiller reinforced composites after biaxial stretching.

The effect of binary carbon nanofillers on the deformation behaviour of the composites during biaxial stretching is shown in Fig. 2a. An obvious strain hardening behaviour is observed for all the composites, which indicates that the deformation stability and thus processability of material are improved with the incorporation of nanofillers. The composite containing $2 \mathrm{wt} \%$ GNPs and $2 \mathrm{wt} \%$ CNTs shows the highest stress during deformation due to the high aspect ratios of GNPs and CNTs. The yield stress and ultimate stress of the HDPE/GNP/CNT composite increased by about $355 \%$ and $440 \%$ respectively upon stretching, compared to the neat HDPE.

The tensile properties of the composites versus SRs are shown in Fig. $2 b$ and c. One can see that the Young's modulus $(E)$ of the $\mathrm{CM}$ composites is greatly improved with the introduction of carbon nanofillers, while their stress at break $\left(\sigma_{b}\right)$ is reduced. Fig. $2 \mathrm{~b}$ shows that the $E$ of the stretched composites increases steadily with increasing SRs due to the deagglomeration and reorientation of nanofillers. Additionally, the $\sigma_{b}$ of all the stretched binary carbon nanofiller reinforced composites is significantly increased, particularly for the stretched HDPE/GNP/CB composites (Fig. 2c). $E$ and $\sigma_{b}$ also increase for the neat HDPE samples up to a SR of 2.5 after which they drop off. This drop is likely to be due to the relaxation of polymer chains prior to solidification which is not observed in the nanocomposite samples due to restricted molecular mobility imposed by the oriented nanofillers [6]. Table 1 shows that the HDPE/GNP/CNT composites exhibit the greatest reinforcement in $E$ due to the high aspect ratios of 
GNPs and CNTs, while the HDPE/GNP/CB composites exhibit the greatest reinforcement in $\sigma_{b}$ after biaxial deformation due to the high aspect ratio of GNPs and the intensive deagglomeration of CB. At a $\mathrm{SR}$ of 3 , the $E$ of the HDPE/GNP/CNT composite increased by about $65 \%$ and the $\sigma_{b}$ of the HDPE/GNP/CB composite increased by about $256 \%$, compared with the unfilled HDPE (Table 1).

The variations in the resistivity of the BS composites with increasing SRs are shown in Fig. 3a. The resistivity of the unstretched HDPE/GNP/CNT and HDPE/CB/CNT composites decreases by 14 and 15 orders of magnitude respectively compared to the unstretched HDPE, while that of the unstretched HDPE/GNP/CB composite only decreases by 4 orders of magnitude. It is clear that the presence of 1dimensional CNTs better facilitate the formation of a conductive network with more interlacing. It can be observed in Fig. 3a that the resistivity of stretched HDPE/GNP/CB composites at all the SRs remains at a high level. The resistivity of the HDPE/GNP/CNT composites increased by 9 to 10 orders of magnitude after biaxial stretching. This is due to the distance between the GNPs and CNTs being higher than the critical maximum distance (1.8 $\mathrm{nm}$ [7]) for electron hopping after biaxial deformation. It appears that the conductive network in the stretched $\mathrm{HDPE} / \mathrm{CB} / \mathrm{CNT}$ composites is more robust than that in the stretched HDPE/GNP/CNT composites, even though the GNPs have much higher aspect ratio than CB. This may be attributed to a synergistic effect between the CNTs and CB, in which the oriented CNTs provide charge transport over large distances and the dispersed CB nanoparticles bridged the CNTs through charge transport over small distances [8].

The oxygen permeability coefficient $\left(P_{g}\right)$ of the CM and BS samples at a SR of 3 was measured to investigate the effect of binary nanofillers and biaxial stretching on barrier properties, as shown Fig. $3 \mathrm{~b}$. The $P_{g}$ of unstretched HDPE/CB/CNT composite shows a slight decrease of around $10 \%$ compared with the neat HDPE. However, the $P_{g}$ of both unstretched HDPE/GNP/CNT and HDPE/GNP/CB composites significantly decreased by about $35 \%$ due to the presence of GNPs which have a very high aspect ratio and typical 2-dimensional structure resulting in an increased tortuosity in the diffusion path of gaseous molecules. The $P_{g}$ of the stretched HDPE and HDPE/CB/CNT composite decreased by approximately $10 \%$ ( $\mathrm{SR}=3$ ) probably due to increased crystallinity of the stretched samples [9]. Importantly, the $P_{g}$ of stretched HDPE/GNP/CNT and HDPE/GNP/CB composites decreased by $88 \%$ and $97 \%$ respectively, compared with the unstretched ones. This demonstrates that the parallel alignment of GNPs to the 
stretching surface improves the barrier property of the composites. The spherical CB served as spacers may facilitate the realignment and deagglomeration of GNPs in the HDPE/GNP/CB composite upon biaxial stretching, resulting in the lowest $P_{g}$ (see the schematic "tortuous path" for the HDPE/GNP/CB composite in Fig. 3b). It should be noted that the realigned nanofillers in the stretched HDPE/GNP/CB composites do not improve the conductivity due to the essential difference in the mechanisms of gas barrier and electrical conduction.

\section{Conclusions}

Biaxial stretching of binary carbon nanofiller reinforced HDPE nanocomposites was carried out at various stretching ratios. It is shown that the strain hardening behaviour of nanocomposites upon biaxial stretching is enhanced with increasing aspect ratios of the nanofillers, greatly improving the deformation stability of the material. The modulus and stress at break of the stretched composites increases with increasing SRs due to the deagglomeration and reorientation of nanofillers, while the conductive network structures in the composites are destroyed to different extents during stretching due to increased interparticle distance. The 2-dimensional GNPs with a very high aspect ratio can greatly improve the barrier properties of the HDPE/GNP/CNT and HDPE/GNP/CB composites, particularly when they are realigned parallel to the stretching surface after biaxial stretching. Generally, the unstretched and stretched HDPE/GNP/CNT composites show the most balanced tensile, electrical and barrier properties.

\section{Acknowledgements}

The authors thank the financial support from SWPU open experiment program (KSZ16106), Science \& Technology Department of Sichuan Province (2017HH0086, 2017JY0152) and Education Department of Sichuan Province (17ZB0462).

\section{References}

[1] Pang H, Chen C, Bao Y, Chen J, Ji X, Lei J, Li ZM. Mater Lett 2012; 64: 96-99.

[2] Xiang D, Wang L, Zhang Q, Chen B, Li Y, E. Harkin - Jones. Polym Compos 2017; DOI: $10.1002 /$ pc. 24328 .

[3] Mayoral B, Hornsby PR, McNally T, Schiller TL, Jack K, Martin, DJ. RSC Adv 2013; 3: 5162-5183. 
[4] Shen J, Champagne MF, Yang Z, Yu Q, Gendron R, Guo S. Compos Part A-Appl S 2012; 43: 14481453.

[5] Xiang D, Harkin-Jones E, Linton D. RSC Adv 2015; 5: 47555-47568.

[6] Xiang D, Harkin-Jones E, Linton D. RSC Adv 2014; 4: 44130-44140.

[7] Li C, Thostenson ET, Chou TW. Appl Phys Lett 2007; 91: 223114-223116.

[8] Wen M, Sun X, Su L, Shen J, Li J, Guo S. Polymer 2012; 53: 1602-1610.

[9] Chatterjee T, Patel R, John Garnett IV, Paradkar R, Ge S, Liu L, Forziati KT, Shah N. Polymer 2014; 55: 4102-4115. 


\section{Figures:}
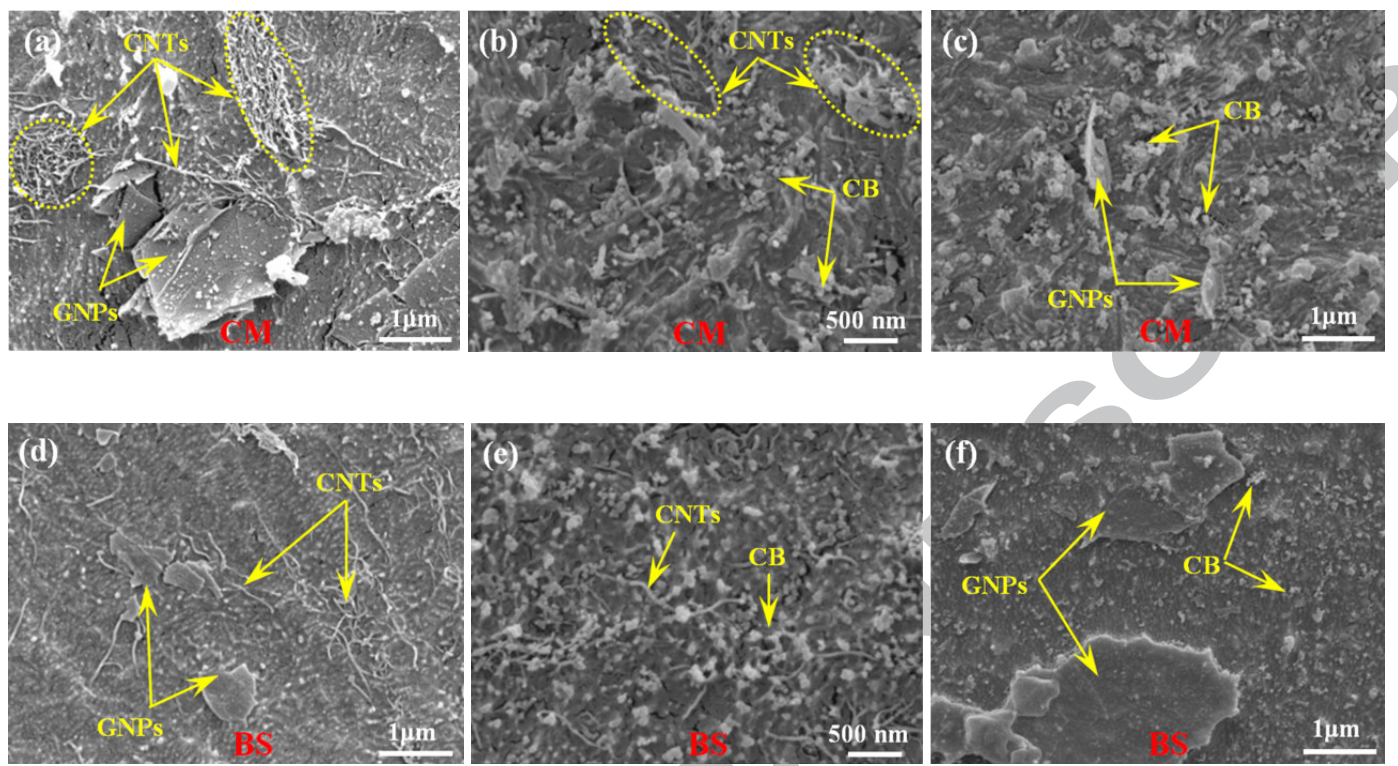

Fig. 1. SEM images of $C M$ and $B S(S R=3$ ) binary carbon nanofiller reinforced composites: $(a, d)$ HDPE/GNP/CNT; (b, e) HDPE/CB/CNT; and (c, f) HDPE/GNP/CB. 

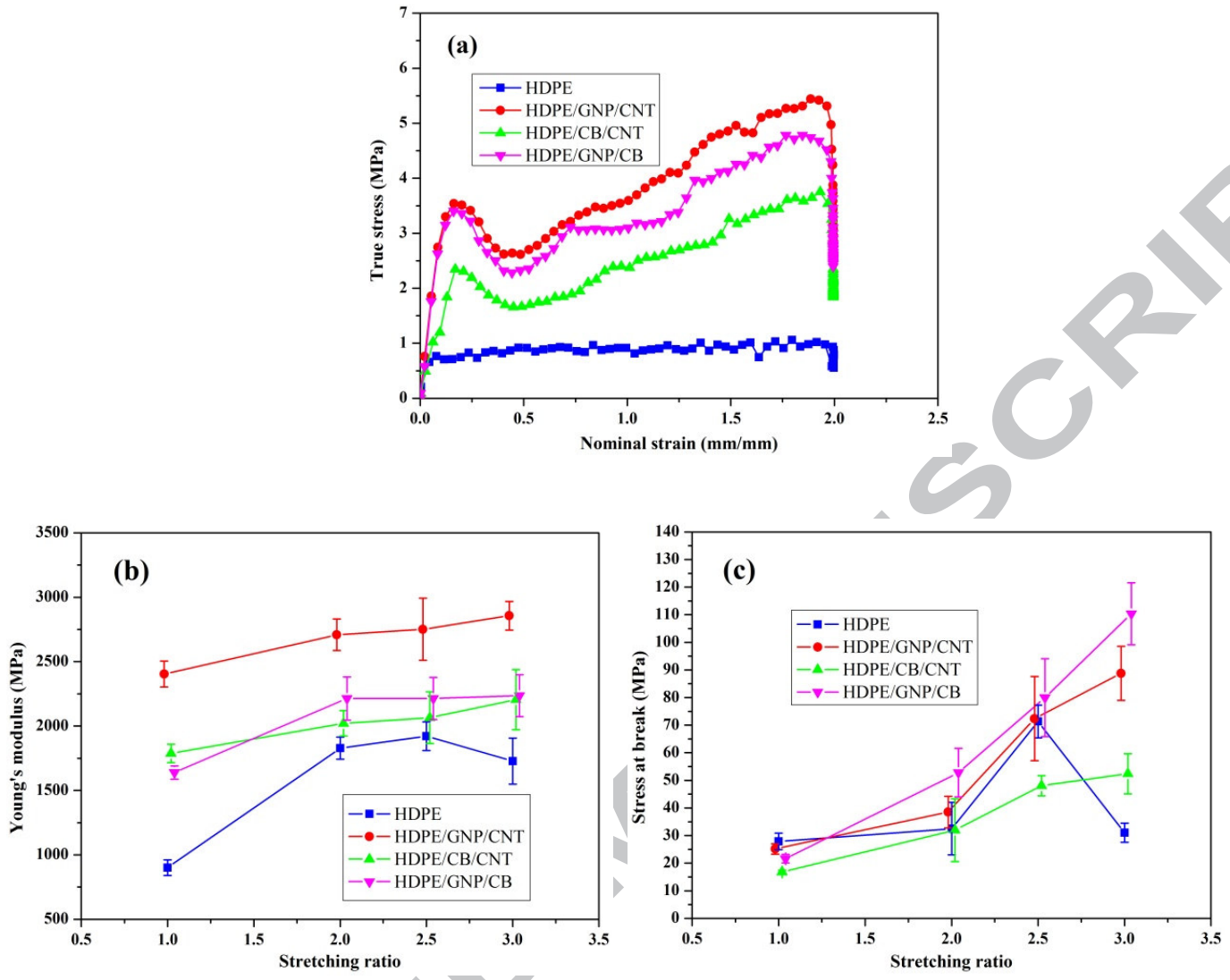

Fig. 2. (a) Strain-stress curves of the composites during biaxial stretching, (b) modulus and (b) stress at break of the composites with increasing SRs. 

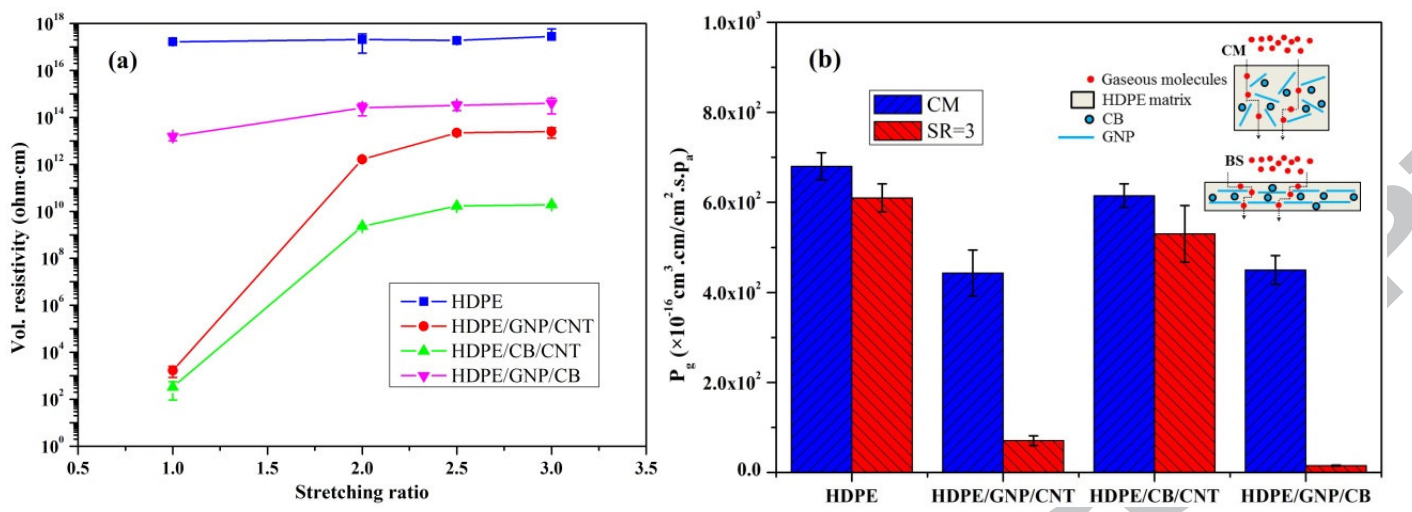

Fig. 3. Effect of biaxial stretching on the (a) resistivity and (b) permeability coefficient of the composites. 
Table:

Table 1. Effect of the binary carbon nanofillers on the tensile properties of composites.

\begin{tabular}{|c|c|c|c|}
\hline Sample & SR & $\Delta \boldsymbol{E}(\%)$ & $\Delta \sigma_{b}(\%)$ \\
\hline \multirow{4}{*}{$\begin{array}{l}\text { HDPE/GNP/CN } \\
\mathrm{T}\end{array}$} & 1 & +166.9 & -9.7 \\
\hline & 2 & +48.1 & \multirow[b]{3}{*}{+186.1} \\
\hline & 2.5 & +43.2 & \\
\hline & 3 & +65.3 & \\
\hline \multirow{4}{*}{$\mathrm{HDPE} / \mathrm{CB} / \mathrm{CNT}$} & 1 & +98.5 & -39.8 \\
\hline & 2 & +10.5 & -1.7 \\
\hline & 2.5 & +7.4 & -32.6 \\
\hline & 3 & +27.6 & +68.8 \\
\hline \multirow{4}{*}{ HDPE/GNP/CB } & 1 & +82.0 & -22.5 \\
\hline & 2 & +21.1 & +62.5 \\
\hline & & +15.2 & +12.2 \\
\hline & & +29.4 & +255.6 \\
\hline
\end{tabular}


- Binary carbon nanofillers reinforced HDPE composites was biaxially stretched (BS).

- The composites show an evident strain hardening behaviour in biaxial deformation.

- The tensile properties of BS composites are steadily improved with increasing SRs.

- Conductive network structures in BS composites are destroyed to different extents.

- The realigned GNPs can greatly enhance the barrier properties of BS composites. 